\title{
Investigating Online Reviews: The Interaction Between Online Review Volume and Valence: An Abstract
}

\author{
Elika Kordrostami, Yuping Liu-Thompkins, and Vahid Rahmani
}

\begin{abstract}
Evidence shows that products with online reviews have a higher chance to stay in the consideration set of consumers than products with no online reviews do. Components of online reviews, such as consumer-generated content, affect consumers' purchase decision-making process. Most of the studies in this area have looked at valence and volume of online reviews. Generally, valence and volume of online reviews are considered to positively influence sales; however, the findings in the literature are inconclusive. While some studies have reported a positive relationship between valence/volume and sales, others have failed to find any significant relationship. In this research, we explain some of these inconsistencies in the literature by investigating the interaction between valence and volume. The results of our study showed that the effects of both valence and volume are contingent on the valence range. While valence has a stronger effect in low and high valence ranges, volume was more important only when valence reached at least the medium level.

Furthermore, this study will enable practitioners to more effectively fine-tune their marketing apparatus. The rise in doing business online requires companies to think about new ways of marketing their product and services, in a way that enables them to skim the online market. The finding of current research can be used as a guideline to companies. The results of our study showed that if generally speaking, the current valence of the item on company's website is highly negative, there is no point in increasing the number of reviews, unless the firms can offer incentives to satisfied customers to postpositive reviews. Then once the valence is within acceptable/medium range, companies should try to increase the number of online reviews as the results of our study have shown that, at medium levels of valence, higher volume has a positive effect on purchase intention.
\end{abstract}

References Available Upon Request

\author{
E. Kordrostami $(\bowtie)$ \\ Humboldt State University, Arcata, CA, USA \\ e-mail: elika.kordrostami@humboldt.edu \\ Y. Liu-Thompkins $\bullet$ V. Rahmani \\ Old Dominion University, Norfolk, VA, USA \\ e-mail:yxxliu@odu.edu; vrahmani@odu.edu
}

(C) Academy of Marketing Science 2018 